\title{
IMATUROS DE PENTATOMÍDEOS (HEMIPTERA, HETEROPTERA): MORFOLOGIA E BIOLOGIA DE ACROSTERNUMOBSTINATUM ${ }^{1}$
}

\author{
Viviana C. Matesco ${ }^{2}$ \\ Nora D. F. Fortes ${ }^{3}$ \\ Jocélia Grazia ${ }^{2}$
}

\begin{abstract}
IMMATURES OF PENTATOMIDS (HEMIPTERA, HETEROPTERA): MORPHOLOGY AND BIOLOGY OF ACROSTERNUM OBSTINATUM. The morphological characteristics of the egg and five immature stages of Acrosternum obstinatum (Stål, 1860), fed on passion fruit, are described and illustrated. Biological data are also provided.
\end{abstract}

KEYWORDS. Pentatomidae, Acrosternum, immatures, morphology, biology.

\section{INTRODUÇÃO}

O estudo dos estágios imaturos de espécies de Pentatomidae, potencialmente importantes no âmbito econômico, vem sendo ampliado. O gênero Acrosternum Fieber, 1860 tem sua distribuição nas regiões Neártica, Neotropical, Etiópica, Paleártica e Oriental (Rolston, 1983); são mais comumente encontrados em Leguminosae, além de aproximadamente 30 famílias de plantas. Das espécies de Acrosternum conhecidas para o continente americano, seis possuem seus estágios imaturos descritos: $A$. bellum Rolston, 1983, A. hilare (Say, 1831), A. impicticorne (Stål, 1872), A. marginatum (Palisot de Beauvois, 1805), A. scutellatum (Distant, 1890) e A. ubicum Rolston, 1983 (Whitmarsh, 1917; Grazia et al., 1982; VeCCHIO et al., 1988; BRAYlovSKy et al., 1992; SCHWERTNER et al., 2002). Este conhecimento é agora ampliado, com a descrição dos estágios imaturos de $A$. obstinatum (Stål, 1860) e novo registro para planta-hospedeira desta espécie.

1. Contribuição n 396 do Departamento de Zoologia, Universidade Federal do Rio Grande do Sul (UFRGS).

2. Departamento de Zoologia, UFRGS, Av. Bento Gonçalves 9.500, Prédio 43435, Sala 223, 91501-970, Porto Alegre, RS, Brasil. Bolsista CNPq. (jocelia@ufrgs.br)

3. Universidade Luterana do Brasil, Rua Miguel Tostes 101, 92420-280, Canoas, RS, Brasil. 


\section{MATERIAL E MÉTODOS}

No período de dezembro de 2000 a março de 2001, 55 adultos ( 21 machos e 34 fêmeas) e 18 ninfas de $5^{\circ}$ instar (13 machos e 5 fêmeas) de $A$. obstinatum foram coletados em maracujá (Passiflora alata Dryander) no bairro Vila Assunção, Porto Alegre, Rio Grande do Sul. Os exemplares foram mantidos em condições ambientais de laboratório, confinados em uma gaiola de madeira e tela de náilon, com $30 \mathrm{~cm}$ de largura, $30 \mathrm{~cm}$ de comprimento e $93 \mathrm{~cm}$ de altura. O alimento consistiu de ramos da planta-hospedeira imersos em água e frutos maduros. A gaiola foi vistoriada diariamente e as posturas foram transferidas para placas de Petri $(9 \mathrm{~cm}$ diâmetro) forradas com papel filtro e contendo um chumaço de algodão umedecido. Para cada postura registraram-se: número de ovos e datas de oviposição, eclosão das ninfas, ecdises e mortes. Após a primeira muda, as ninfas foram transferidas para potes plásticos (12 cm diâmetro; 7,5 cm altura), com tampa telada e contendo algodão umedecido ou para garrafas plásticas (250 ou $500 \mathrm{ml}$ ), com armação de arame, envoltas por sacos de filó (Gilson R. P. Moreira, com. pess.). Ninfas provenientes da mesma postura foram mantidas juntas até o final do experimento. Como alimento, ofereceram-se pedaços de maracujá, ramos e frutos inteiros. Tanto para as ninfas quanto para os adultos, os ramos de maracujá eram substituídos uma vez por semana, assim como os frutos, quando apresentassem sinais de senescência ou estivessem em estágio de maturação avançada. Durante todo o experimento, as placas de Petri, os potes e as garrafas plásticas foram mantidos em câmara climatizada (B.O.D.), com temperatura e fotoperíodo controlados $\left(21,9 \pm 1{ }^{\circ} \mathrm{C}\right.$; $12 \mathrm{hL}: 12 \mathrm{hE}$ ) e umidade relativa média de $63 \pm 7 \%$.

De cada instar, retiraram-se 10 exemplares, à exceção do $5^{\circ}(\mathrm{n}=8)$, além de uma postura com 14 ovos, para fixação em álcool etílico $70 \%$, os quais serviram para o estudo da morfologia externa. $\mathrm{O}$ material foi depositado na coleção do Departamento de Zoologia, Universidade Federal do Rio Grande do Sul. A descrição da coloração foi feita com base em exemplares vivos. As medidas, tomadas com auxílio de ocular de medição, estão expressas em milímetros, correspondendo a média e desvio padrão (tab. I). Foram realizadas medidas correspondentes ao comprimento total ao longo da linha mediana longitudinal; comprimento da cabeça; comprimento do tórax (no maior comprimento, incluindo as pterotecas no $4^{\circ}$ e $5^{\circ}$ ínstares); largura da cabeça no nível dos olhos; distância interocular na altura mediana dos olhos; maior largura do tórax; largura abdominal no nível do segmento III no $1^{\circ}$ instar e, nos demais ínstares, no nível do segmento II, e comprimento dos artículos antenais em vista dorsal.

\section{RESULTADOS E DISCUSSÃO}

Ovo (figs. 1, 2). Castanho-claro, em forma de barril. Cório branco-translúcido, com superfície granulosa. Processos micropilares translúcidos, clavados no ápice. Número de processos micropilares: 72,4 (63-86). Largura 1,3 $\pm 0,13$; altura 1,7 $\pm 0,14$. Opérculo convexo. Ruptor ovis translúcido, castanho-escuro na base e ao longo da linha mediana, de forma triangular.

$1^{\circ}$ instar (figs. 3, 6). Ovalado, superfície destituída de pontuação. Coloração geral negra, incluindo olhos, pernas e antenas, exceto uma mancha ovalada alaranjada, disposta centralmente no protórax e terço basal da cabeça, e manchas amareladas e brancas no abdome. Pêlos uniformemente distribuídos sobre o corpo, mais longos e densos nas extremidd des das antenas e pernas. Cabeça fortemente declivente na metade anterior, mais larg do que longa. Clípeo com ápice arredondado, pouco ultrapassa as jugas, estas arredondadas no ápice. Ocelos ausentes. Artículos antenais I-III cilíndricos; IV fusiforme; II mais lo ggo que o I e o III; IV mais longo que os demais. Rostro negro, ultrapassa as metacoxa . Margens laterais do pro-, meso- e metatórax defletidas. Tíbias dorsalmente aplainada, ventralmente arredondadas. Maior largura no segmento abdominal III. Dorso abdomina com $1+1$ amplas manchas amareladas, semi-ovaladas, recobrindo os segmentos II e III, en tre as placas laterais e medianas; manchas brancas: uma circundando cada uma das placa laterais; outra ao longo da linha mediana longitudinal, interrompida pelas 
Tabela I. Medidas dos parâmetros morfométricos (média \pm DP; $\mathrm{mm}$ ) dos cinco ínstares ninfais de Acrosternum obstinatum (Stål, 1860) (I, II, III, IV, comprimento dos artículos antenais; CC, comprimento da cabeça; CT, comprimento total; CTO, comprimento do tórax; DI, distância interocular; LA, largura abdominal; LC, largura da cabeça; LT, largura do tórax; n, número de exemplares medidos).

\begin{tabular}{cccccc}
\hline & $\begin{array}{c}1^{\circ} \text { instar } \\
(\mathrm{n}=10)\end{array}$ & $\begin{array}{c}2^{\circ} \text { instar } \\
(\mathrm{n}=10)\end{array}$ & $\begin{array}{c}3^{\circ} \text { instar } \\
(\mathrm{n}=10)\end{array}$ & $\begin{array}{c}4^{\circ} \text { instar } \\
(\mathrm{n}=10)\end{array}$ & $\begin{array}{c}5^{\circ} \text { instar } \\
(\mathrm{n}=8)\end{array}$ \\
\hline CT & $2,1 \pm 0,17$ & $3,4 \pm 0,26$ & $4,7 \pm 0,53$ & $6,4 \pm 0,44$ & $8,1 \pm 0,41$ \\
CC & $0,5 \pm 0,10$ & $0,7 \pm 0,08$ & $0,9 \pm 0,11$ & $1,1 \pm 0,18$ & $1,2 \pm 0,16$ \\
CTO & $0,6 \pm 0,07$ & $1,2 \pm 0,08$ & $1,7 \pm 0,14$ & $2,5 \pm 0,15$ & $3,6 \pm 0,18$ \\
LA & $1,7 \pm 0,14$ & $2,5 \pm 0,26$ & $3,6 \pm 0,53$ & $5,0 \pm 0,23$ & $6,3 \pm 0,49$ \\
LT & $1,5 \pm 0,08$ & $2,4 \pm 0,12$ & $3,3 \pm 0,37$ & $4,6 \pm 0,29$ & $6,0 \pm 0,53$ \\
LC & $0,9 \pm 0,05$ & $1,3 \pm 0,05$ & $1,7 \pm 0,10$ & $2,3 \pm 0,11$ & $2,6 \pm 0,11$ \\
DI & $0,6 \pm 0,12$ & $0,9 \pm 0,03$ & $1,2 \pm 0,09$ & $1,4 \pm 0,11$ & $1,6 \pm 0,04$ \\
I & $0,1 \pm 0,04$ & $0,2 \pm 0,00$ & $0,3 \pm 0,04$ & $0,4 \pm 0,06$ & $0,5 \pm 0,08$ \\
II & $0,2 \pm 0,05$ & $0,6 \pm 0,05$ & $0,9 \pm 0,07$ & $1,3 \pm 0,08$ & $1,7 \pm 0,11$ \\
III & $0,3 \pm 0,06$ & $0,5 \pm 0,05$ & $0,8 \pm 0,04$ & $1,1 \pm 0,07$ & $1,4 \pm 0,08$ \\
IV & $0,5 \pm 0,07$ & $0,8 \pm 0,05$ & $1,0 \pm 0,08$ & $1,3 \pm 0,08$ & $1,6 \pm 0,06$ \\
\hline
\end{tabular}

placas medianas, e 1+1 manchas alares junto à segunda e terceira placas medianas. Em alguns exemplares, presente uma linha alaranjada delimitando as placas laterais, a primeira placa mediana do abdome e a margem posterior do metatórax. Espiráculos torácicos nos dois primeiros segmentos. Espiráculos abdominais nos segmentos II a VIII, situados próximos às placas laterais e mais próximos da margem anterior dos segmentos. Um tricobótrio nos segmentos III a VII, em posição interna e posterior aos espiráculos.

$2^{\circ}$ instar (fig. 7). Ovalado, coloração geral negra, exceto mancha retangular alaranjada junto à borda lateral do protórax, com escassa pontuação enegrecida, distribuída uniformemente pela cabeça, tórax e placas abdominais, e manchas amareladas e brancas no abdome. Pêlos longos e densos nas extremidades das antenas e pernas. Cabeça moderadamente declivente na metade anterior. Margens laterais do pro- e mesotórax fortemente serrilhadas. Maior largura no segmento abdominal II. Manchas amareladas do dorso abdominal mais amplas, arredondadas, estendendo-se do segmento I ao III. Manchas brancas: uma circundando apenas a primeira placa lateral; três manchas circulares situadas anteriormente a cada uma das três primeiras placas medianas; manchas alares apenas junto à terceira placa mediana e $1+1$ pequenas manchas circulares laterais à quarta placa mediana. Abdome ventralmente com mancha negra longitudinal mediana sobre os segmentos IV ao VIII; esta mancha amplia-se progressivamente até o segmento VI, estreitando-se em direção ao ápice. Um par de tricobótrios nos segmentos III ao VII; tricobótrio externo na linha dos espiráculos. Demais características como descrito no instar anterior.

$3^{\circ}$ instar (fig. 8). Ovalado, coloração gera negra. Pontuçãa escassa $n \mathbf{p}$ abdome, concentrada nos seg mentos III ao $\mathrm{V}$, entre as plac s laterais e me ianas. Dorso do abdome com manchas semi-pvaladas, am reladas sobre $\mathbf{s}$ segmentos I to III. Manch $\$$ brancas: além daquelas exist ntes no $2^{\circ}$ ins ar, uma circula anteriormente à quarta placa mediana $\mathrm{e}$ $1+1$ circulares men res, próximas às placas latorais dos segm ntos IV e V. Im alguns exemplares, uma cir ular alaranja a no centro de ada placa later 1. Demais características como descrito no in tar anterior. 
$4^{\circ}$ instar (fig. 9). Ovalado, coloração geral negra. Jugas ultrapassam sutilmente o clípeo. Artículos antenais II e IV subiguais em comprimento. Margens laterais do pro- e mesotórax levemente serrilhadas. Mesotórax levemente intumescido, margem posterior medianamente em "V" aberto, iniciando a formação do escutelo. Pterotecas atingem a margem posterior do metatórax. Manchas amareladas do dorso abdominal recobrem os segmentos I ao IV. Manchas brancas: $1+1$ circulares, próximas à placa lateral dos segmentos I e VII. Mancha circular alaranjada no centro de cada placa lateral. Abdome ventralmente com $1+1$ pequenas manchas brancas circulares, anteriormente aos espiráculos. Demais características como descrito no instar anterior.

$5^{\circ}$ instar (figs. 4, 5, 10). Ovalado, coloração geral negra. Pontuação no abdome mais densa nos cinco primeiros segmentos. Manchas alaranjado-escuras, em faixa, na região anterior das jugas. Ocelos presentes. Segundo artículo antenal maior do que os demais. Protórax medianamente intumescido; margens laterais nitidamente defletidas. Pterotecas desenvolvidas, atingindo a margem posterior do segmento abdominal III. Manchas alaranjadas: $1+1$ retangulares na metade anterior das margens laterais do protórax; $1+1$ na base das pterotecas, e uma subtriangular ao longo da linha mediana do escutelo, estas últimas de coloração alaranjado-escura. Às vezes, também presente uma pequena mancha da mesma cor junto à margem posterior do protórax. Abdome dorsalmente com as manchas amareladas, entre as placas laterais e medianas, recobrindo os segmentos II a III. Manchas brancas circulares próximas à placa lateral restritas aos segmentos abdominais IV, V e VII; mancha circular alaranjada no centro das placas laterais, e mancha alaranjado-escura no centro das três primeiras placas medianas. Todas as manchas alaranjadas ampliam-se ao longo do desenvolvimento das ninfas deste instar, podendo cobrir quase inteiramente a cabeça e o tórax. Demais características como descrito no instar anterior.

Genitália da fêmea (fig. 4). Segmento abdominal VIII ventralmente fendido no meio. Genitália do macho (fig. 5). Segmento abdominal VIII inteiro.

Diagnose diferencial. As ninfas de A. obstinatum destacam-se por apresentarem, em todos os ínstares, coloração geral negra. São também diagnósticos para a espécie a forma, o tamanho e a coloração das manchas dorsais do tórax e do abdome.

Nos três primeiros ínstares, as ninfas das espécies neotropicais de Acrosternum são bastante semelhantes, especialmente no que diz respeito ao padrão de manchas e à coloração (SCHWERTNER et al., 2002). Na ninfa de $1^{\circ}$ instar de $A$. obstinatum, a mancha central, ovalada, na base da cabeça, que se estende ao tórax, é alaranjada, assim como em A. ubicum; nas demais espécies neotropicais (A. bellum, A. impicticorne, A. marginatum e A. scutellatum), é amarelada. Apenas em A. obstinatum e em A. bellum, as 1+1 manchas maiores do dorso abdominal, entre as placas laterais e medianas, têm coloração amarelada; nas demais espécies, esta mancha tem coloração branca no $1^{\circ}$ instar e somente em $A$. scutellatum tornam-se amareladas já no $2^{\circ}$ instar. Em A. bellum, os olhos são vermelhos e os três primeiros artículos antenais têm áreas claras na base e no ápice; A. obstinatum tem os olhos e as antenas negras.

Nas ninfas de $2^{\circ}$ e $3^{\circ}$ ínstares, a mancha dorsal que surge junto à borda lateral do protóra e, às vezes, do mesotórax, tem coloração alaranjada em A. obstinatum, enquanto que em 1. scutellatum ela é amarelo-alaranjado pálido; em A. ubicum, vermelho-alaranjada, e nas de mais espécies, amarelada. As ninfas de $3^{\circ}$ instar de $A$. marginatum são facilmente diferen iadas de A. obstinatum por apresentarem as três quartas partes distais da cabeça, os dois primeiros artículos antenais e parte das pernas amarelas. 

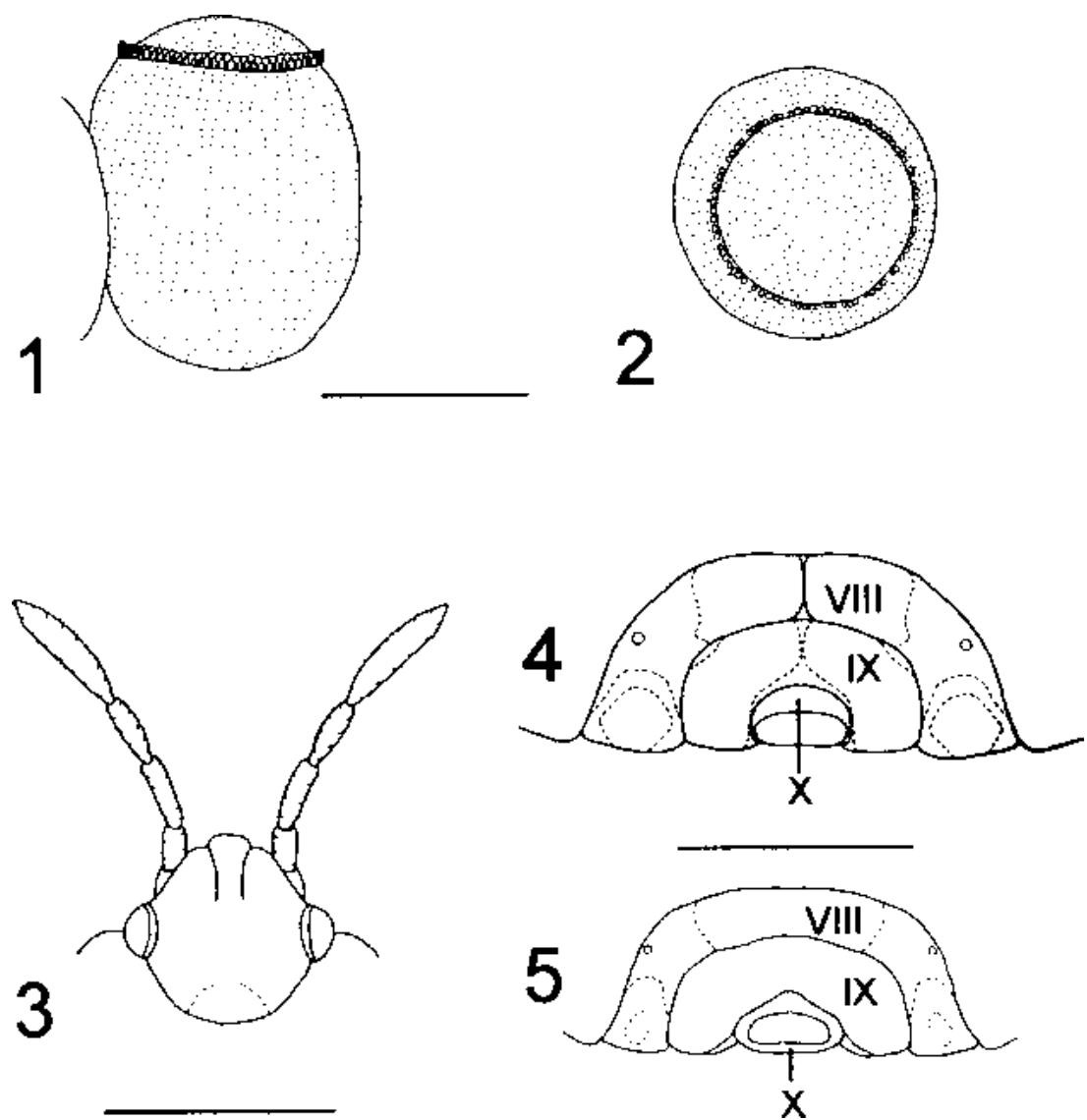

Figs. 1-5. Acrosternum obstinatum (Stål, 1860). Ovo: 1, lateral; 2, dorsal; 3, cabeça da ninfa de $1^{\circ}$ instar, dorsal; 4, genitália externa da fêmea de $5^{\circ}$ instar; 5 , genitália externa do macho de $5^{\circ}$ instar (VIII, oitavo segmento abdominal; IX, nono segmento abdominal; X, décimo segmento abdominal). Escala, $1 \mathrm{~mm}$.

No $4^{\circ}$ e $5^{\circ}$ ínstares, as diferenças entre as espécies mostram-se mais evidentes e baseiamse principalmente na coloração das manchas. Acrosternum bellum é a única espécie cujos ângulos póstero-laterais do protórax são desenvolvidos. O centro das placas laterais é amarelado em A. impicticorne, A. marginatum e A. scutellatum; de vermelho intenso a vermelho-alaranjado em A. ubicum e alaranjado em A. obstinatum. Em A. impicticorne, as manchas dorsais do abdome têm forma sub-retangular. Em A. ubicum, estas manchas são arredondadas como em $A$. obstinatum, porém maiores, e o abdome tem coloração dorsal avermelhada (GrAZIA et al., 1982; VECCHIO et al., 1988; BRAILOVSKY et al., 1992; SCHWERTNER et al., 2002).

Em A. hilare, o dorso do abdome apresenta listras transversais azuis e amarelas nos quatro primeiros ínstares e coloração inteiramente creme no $5^{\circ}$ instar (WHITMARSH, 1917), diferindo de A. obstinatum, assim como de todas as espécies neotropicais conhecidas.

Dados biológicos. Registra-se pela primeira vez a ocorrência de Acrosternum 
Tabela II. Duração média do estágio de ovo e dos cinco ínstares ninfais de Acrosternum obstinatum (Stål, 1860) em Passiflora alata, em condições controladas $\left(21,9 \pm 1^{\circ} \mathrm{C} ; 63\right.$ $\pm 7 \%$ UR; 12 horas de fotofase).

\begin{tabular}{lccc}
\hline & $\begin{array}{c}\mathrm{N}^{\circ} \\
\text { indivíduos }\end{array}$ & $\begin{array}{c}\text { Duração (dias) } \\
\text { (média } \pm \mathrm{DP})\end{array}$ & $\begin{array}{c}\text { Valores extremos } \\
\text { (dias) }\end{array}$ \\
\hline Ovo & 602 & $8,4 \pm 1,66$ & $2-12$ \\
$1^{\circ}$ instar & 569 & $5,6 \pm 1,09$ & $3-8$ \\
$2^{\circ}$ instar & 219 & $13,4 \pm 3,09$ & $6-24$ \\
$3^{\circ}$ instar & 49 & $10,7 \pm 3,68$ & $6-24$ \\
$4^{\circ}$ instar & 9 & $13,4 \pm 4,25$ & $8-22$ \\
$5^{\circ}$ instar & 1 & $26,0 \pm 0,00$ & \\
Ovo a Adulto & 1 & 86 & \\
\hline
\end{tabular}

(Chinavia) obstinatum (Stål, 1860) em maracujá (Passiflora alata Dryander).

Dado o número de posturas obtido, 53 (num total de 700 ovos), pode-se inferir que a alimentação para os adultos utilizada no laboratório foi adequada. A obtenção de apenas um adulto (tab. II) proveniente da criação demonstra a carência nutricional da alimentação fornecida às ninfas.

Apesar da planta utilizada como alimento para adultos e ninfas ser a mesma, apenas as ninfas colocadas nas garrafas plásticas e os adultos receberam os ramos da plantahospedeira. Ao longo do experimento, os ramos mostraram-se importantes fontes nutricionais para o desenvolvimento dos imaturos. Na gaiola, observaram-se os adultos alimentando-se tanto do fruto maduro quanto da haste da planta, com nítida preferência pelos botões florais.

Das 53 posturas, 41 delas $(77,4 \%)$ foram depositadas nas estruturas da gaiola. A tela de náilon foi o local preferido, com 38 posturas $(71,7 \%)$; as três restantes $(5,7 \%)$ foram depositadas na armação de madeira. As garrafas plásticas contendo o alimento serviram como substrato para 10 posturas $(18,8 \%)$. Apenas uma postura $(1,9 \%)$ foi encontrada sobre o fruto do maracujá e outra sobre a gavinha da planta. VeCCHIO \& GRAZIA (1992) relataram um número significativamente maior de posturas sobre a tela das gaiolas do que nas plantas hospedeiras, relacionando este fato à maior disponibilidade de área para oviposição.

O número médio de ovos por postura foi de 13,2 $\pm 3,51$. Existe uma expressiva variação no tamanho da postura, cujo intervalo foi de 3 a 29 ovos por postura, porém $53 \%$ das posturas continham 14 ovos, demonstrando ser este o número mais comum. A taxa de eclosão foi de $88 \%$. Quarenta e seis por cento das posturas tiveram $100 \%$ de emergência. A menor emergência foi $31 \%$. Quarenta e cinco das 52 posturas nas quais se observou desenvolvimento pós-embrionário $(86 \%)$ tiveram emergência $\geqslant 70 \%$.

As fêmeas coletadas no campo, de idades desconhecidas, não foram individualizadas nem marcadas, impossibilitando a obtenção de dados tais como fecundidade, períodos de pré-oviposição, oviposição e pós-oviposição, número de ovos e de posturas por fêmea e intervalo entre oviposições.

A duração média, em dias, do estágio de ovo foi de $8,4 \pm 1,66$, variando de 2 a 12 dias (tab. II). Logo an ós a eclosão, as ninfas de todos os ínstares apresentaram coloração ałaranjada brilhan te, que se torna gradativamente mais escura. Em aproximadamente uma hora, as ninfas ad escrito anteriorn ente. A duração média dos cinco ínstares ninfais de A. obstinatum (tab. I) evidencia que esta espécie não se enquadra perfeitamente na generalização feita por ECOURSEY \& Es Elbaugh (1962) para a duração dos íntares em Pentatomidae, uma vez que a duração do $\beta^{\circ}$ instar é mais curta que a do $2^{\circ}$.

Quanto ao comportamento, as ninfas de A. obstinatum seguem o padrão geral opservado para Pentatomidae. Logo após a eclosão, as ninfas de $1^{\circ}$ instar apresentam 


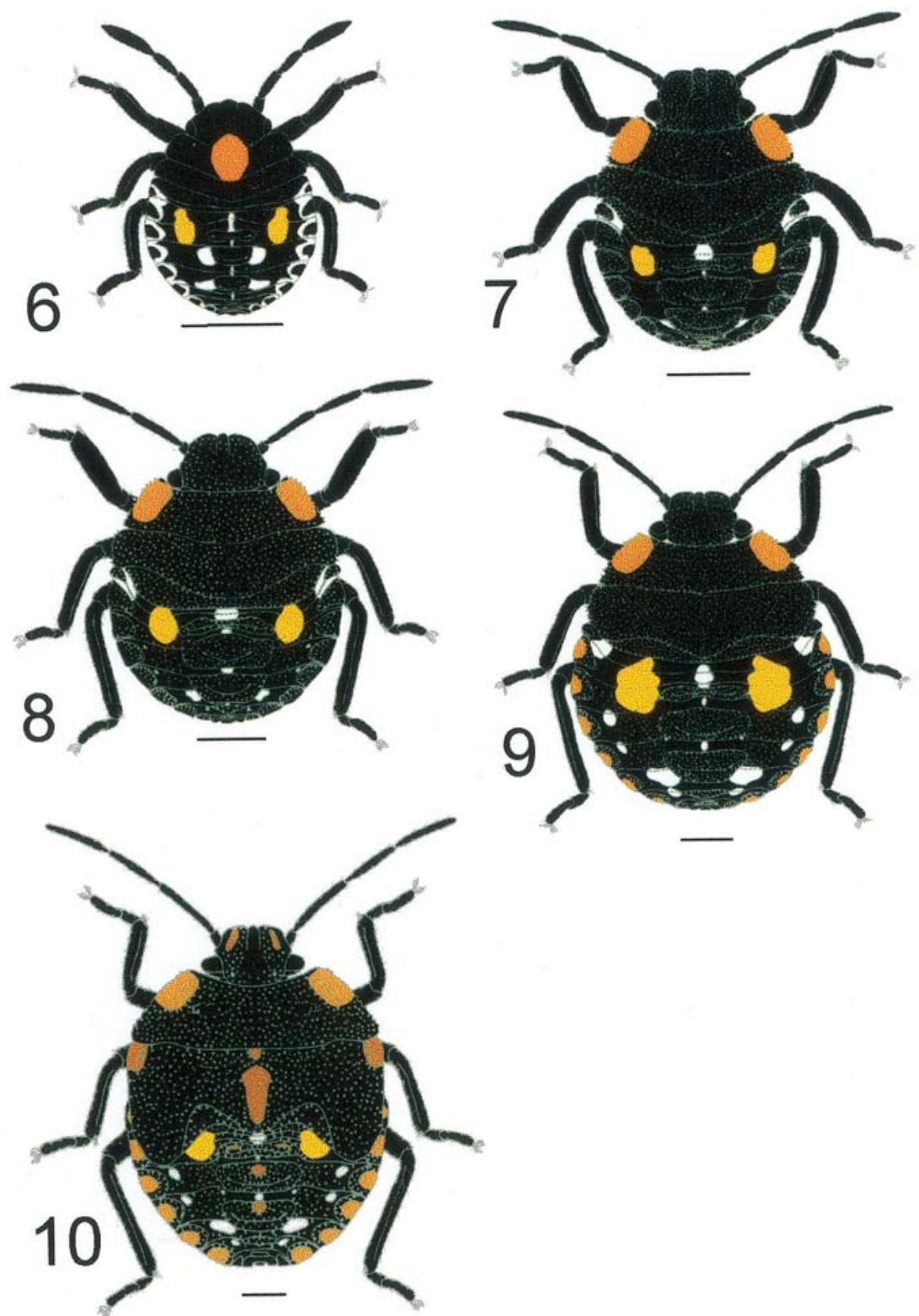

Figs. 6-10. Morfologia externa das ninfas de Acrosternum obstinatum (Stål, 1860): 6, $1^{\circ}$ instar; 7, $2^{\circ}$ instar; $8,3^{\circ}$ instar; $9,4^{\circ}$ instar; $10,5^{\circ}$ instar. Escala, $1 \mathrm{~mm}$. 
comportamento gregário, não se alimentam e permanecem reunidas sobre os córios. A partir do $2^{\circ}$ instar, as ninfas se dispersam em busca de alimento. Das nove ninfas de $5^{\circ}$ instar obtidas, sete eram machos e duas fêmeas, o que corresponde a uma razão sexual de 0,78 (3,5 machos : 1 fêmea). O único adulto obtido era um macho.

A partir desta criação, na qual o alimento oferecido foi exclusivamente Passiflora alata, não se constatou a ocorrência de formas distintas (formas claras e formas escuras) para as ninfas de $A$. obstinatum, tal como descrito para $A$. bellum, A. hilare, A. impicticorne e A. ubicum (Whitmarsh, 1917; Miner, 1966; Vecchio et al., 1988; SChwertner et al., 2002). A ocorrência de formas claras e escuras de ninfas de $4^{\circ}$ e $5^{\circ}$ ínstares pode estar relacionada à oferta de diferentes alimentos às formas jovens (SCHWERTNER et al., 2002).

Agradecimentos. A Leonardo Mohr e familiares, pela disponibilização do local de coleta e dos ramos de maracujá. Ao Dr. Gilson R. P. Moreira, pelo empréstimo de gaiolas e garrafas plásticas para criação dos insetos. A Caroline Greve, pelo auxílio durante a criação e as coletas.

\section{REFERÊNCIAS BIBLIOGRÁFICAS}

Brailovsky, H.; Cervantes, L. \& Mayorga, C. 1992. Hemiptera: Heteroptera de Mexico XliV. Biología, estadios ninfales y fenología de la tribu Pentatomini (Pentatomidae) en la Estación de Biología Tropical "Los Tuxtlas", Veracruz. Mexico, D.F., Universidad Nacional Autonoma de Mexico, Instituto de Biología. 204p. (Publicaciones especiales 8)

Decoursey, M. R. \& Esselbaugh, C. O. 1962. Descriptions of the nymphal stages of some North American Pentatomidae (Hemiptera-Heteroptera). Ann. ent. Soc. Am., College Park, 55:323-342.

Grazia, J.; Vecchio, M. C. del \& Hildebrand, R. 1982. Estudo das ninfas de pentatomídeos (Heteroptera) que vivem sobre soja [Glycine max (L.) Merrill]: IV - Acrosternum impicticorne (Stål, 1872). Anais Soc. ent. Bras., Jaboticabal, 11(2):261-268.

Miner, F. D. 1966. Biology and control of stink bugs on soybeans. Arkansas Agric. Exp. Stn Bull., Fayetteville, (708):1-40.

Rolston, L. H. 1983. A revision of the genus Acrosternum Fieber, subgenus Chinavia Orian, in the Western Hemisphere (Hemiptera, Pentatomidae). JI N. Y. ent. Soc., New York, 91(2):97-176.

Schwertner, C. F.; Albuquerque, G. S. \& Grazia, J. 2002. Descrição dos estágios imaturos de Acrosternum (Chinavia) ubicum Rolston, 1983 (Heteroptera: Pentatomidae) e efeito do alimento no tamanho e coloração da ninfas. Neotrop. Ent., Londrina, 31(4):571-579.

Vecchio, M. C. Del \& Grazia, J. 1992. Obtenção de posturas de Oebalus ypsilongriseus (De Geer, 1773) em laboratório (Heteroptera: Pentatomidae). Anais Soc. ent. Bras., Porto Alegre, 21(3):367-373.

Vecchio, M. C. del; Grazia, J. \& Hildebrand, R. 1988. Estudo dos imaturos de pentatomídeos (Heteroptera) que vivem sobre soja [Glycine max (L.) Merrill]: V - Acrosternum bellum Rolston, 1983 com a descrição da genitália da fêmea. Anais Soc. ent. Bras., Porto Alegre, 17(2):467-482.

Whitmarsh, R. D. 1917. The green soldier bug. Ohio Agric. Exp. Stn Res. Bull., Wooster, (310):519-552.

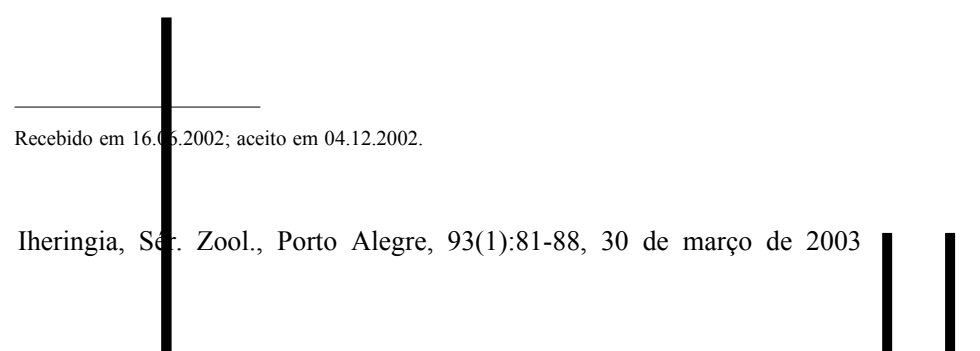

